\title{
CFD Analysis of Charge Exchange in an Aircraft Opposed- Piston Diesel Engine
}

\author{
Zbigniew Czyż ${ }^{1, *}$, Ksenia Siadkowska ${ }^{2}$, and Rafat Sochaczewski ${ }^{3}$ \\ ${ }^{1}$ Polish Air Force University, Aeronautics Faculty, 35 Dywizjonu 303 St., 08-521 Dęblin, Poland \\ ${ }^{2}$ Lublin University of Technology, Faculty of Mechanical Engineering, Department of Thermodynamics, Fluid Mechanics \\ and Aviation Propulsion Systems, Nadbystrzycka 36 Str., 20-618 Lublin, Poland \\ ${ }^{3}$ Pope John Paul II State School of Higher Education in Biała Podlaska, Sidorska 95/97, 21-500 Biała Podlaska, Poland
}

\begin{abstract}
The paper presents a description of geometric models, computational algorithms, and results of numerical analysis of charge exchange in an opposed-piston two-stroke engine. The research engine is a newly designed internal diesel engine. This unit is composed of three cylinders in which operate three pairs of opposed-pistons. The engine generates a power output equal to $100 \mathrm{~kW}$ at a crankshaft rotation speed of 3800-4000 rpm. The numerical investigations were carried out using ANSYS FLUENT solver. The geometrical model includes an intake manifold, a cylinder and an outlet manifold. The study was conducted for a series of modifications of manifolds and intake and exhaust ports to optimise the charge exchange process in the engine. In addition, we attempted to verify the effect of the combustion chamber shape on the charge exchange process in the engine. The calculations specified a swirl coefficient obtained under steady conditions for fully open intake and exhaust ports as well as the CA value of $280^{\circ}$ for all cylinders. In addition, mass flow rates were identified separately in all of the intake and exhaust ports to achieve the best possible uniformity of flow in particular cylinders. The paper includes comparative analyses of all of the intake and exhaust manifolds of the designed engine.
\end{abstract}

\section{Introduction}

Compression-ignition engines are not widely used in aviation as this sector is dominated by jet turbine engines and turboshaft engines: the main reason is the relatively high power-to-weight ratio [1, 2, 3, 4]. In the 1940s, when aircraft compression-ignition engines began to be developed, turbojet and turboprop engines appeared and successfully satisfied the contemporary demands of aviation. Progress in the development of diesel automotive engines was also reflected in aircraft engines and therefore diesel aircraft engines enjoyed their revival in the $21^{\text {st }}$ century [5]. An opposed-piston engine is an interesting technological construction in the compression ignition aircraft engines family, which has been the subject of numerous research works, such as $[6,7,8]$.

The first opposed-piston engine was constructed in 1890. Unlike four-stroke engines, this engine design includes no head and valves, which are considered to be its most expensive parts. Jumo Junkers, designed and developed by professor Hugo Junkers for the German army and civil aviation from 1930-45, is considered to be one of the most significant developments among opposed-piston engines [9].

Despite their numerous advantages, opposed-piston engines had one disadvantage, i.e. high emissions that put their development on hold for many years. Since early 1980s all commercially available engines have been subject to emission standards for all engine vehicles, which has blocked the development of these engines mainly due to their inefficient fuel injection system and non-optimise d combustion chamber geometry. Technological progress and modern designing methods have enabled their market come-back. Today, the highly developed CFD calculation technique enables optimisation of such processes as: heat exchange [10] and charge exchange, forming a blend [11], combustion in the engine $[12,13]$, and modelling of the injection process [14]. Paper [18] contains information regarding the aircraft engine operation conditions, whereas [19] describes the combustion in engine, which is also relevant to this article. Numerical analysis, in contrast to experimental research, enables validating design assumptions and avoid costly prototype preparation for experimental tests; consequently, the geometrical model can be optimise $d$ in countless variants not generating any production costs.

Modern innovative methods such as artificial neural networks and genetic algorithms are also rapidly developing [15]. These tools were unavailable for engineers in the previous century, which is why engine manufacturers nowadays are reaching out to older but proven engine designs to improve them now.

Numerous studies aimed to optimise the operation of internal combustion engines are conducted, e.g. the scavenging process in a two-stroke free piston linear

${ }^{*}$ Corresponding author: z.czyz@law.mil.pl 
engine has been modelled and simulated successfully based on the combination of a dynamic model and a CFD model, see [16]. The authors of [17] reviewed in detail conventional internal combustion engines and indicated two-stroke ones as investigated most frequently for their advantageous construction and control.

\section{Problem description and objective}

The main aim of this paper is to design an intake and exhaust manifolds for the optimization of charge exchange in an opposed-piston two-stroke engine shown in Figure 1. Particular-case calculation time is fundamental for calculations.

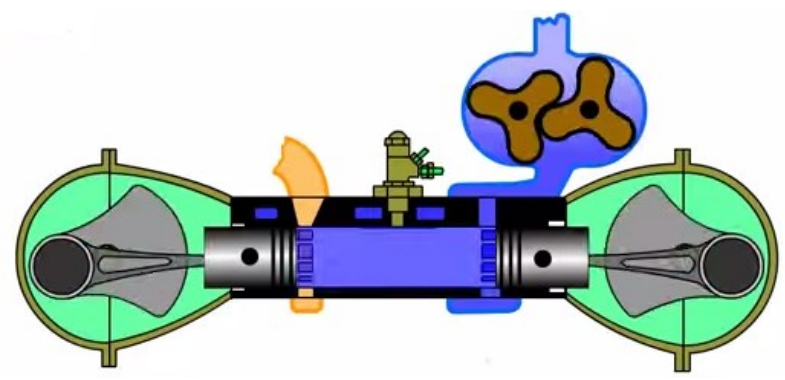

Fig. 1. Schematic of an opposed-piston engine.

The investigated engine was a newly designed twostroke internal diesel engine. The unit's characteristic feature is three cylinders with three pairs of opposedpistons (Fig. 2). The engine will generate a power output equal to $100 \mathrm{~kW}$ at a crankshaft rotation speed of 3800 $4000 \mathrm{rpm}$ with a capacity of about 1.61 in a diesel cycle. The engine will be equipped with a direct diesel injection system. This paper shows a description of geometric models, computational algorithms and results of numerical analyses.

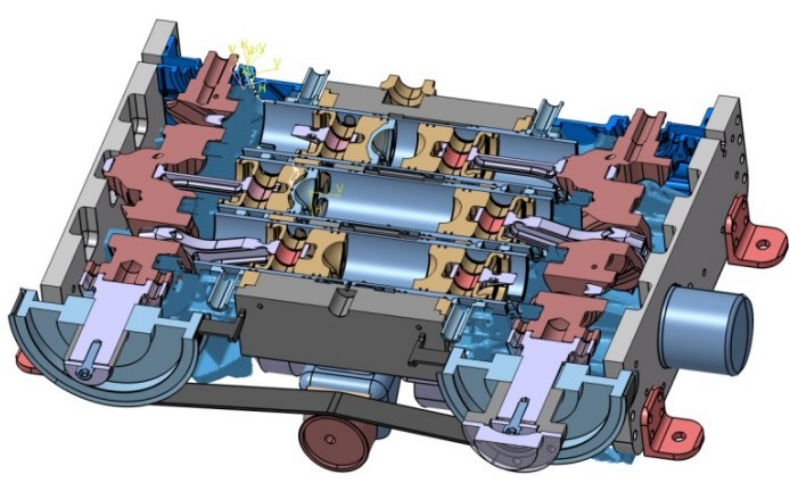

Fig. 2. New construction of the opposed-piston engine.

For the models under consideration, velocity, pressure and streamlined contours were generated in important cross-sections. The developed models are designed primarily to minimise the flow drag through the intake and exhaust ports at the increased mass flow rate. Firstly, in order to calculate the swirl ratio [-], tangential velocity $\mathrm{v}[\mathrm{m} / \mathrm{s}]$ and then angular velocity $\omega[\mathrm{rad} / \mathrm{s}]$ with respect to the charge, the mean averages of each quantity were calculated.
The calculations given here were carried out for two geometric models with different piston crowns (flat and specially-shaped). Flat piston crowns function as a reference for the proposed model with specially-shaped piston crowns (Fig. 3). Piston crowns have been shaped according to the given process of combustion in the engine (Fig. 4). The model has three cylinders for which the mass flow rate was recorded particularly for all inlet and outlet ports as a function of time. The obtained results enabled us to create mass flow rate charts for each of the cylinders, accompanied by the contours of pressure and velocity in the selected sections. Moreover, our results are compared to the identical version calculated for steady conditions.

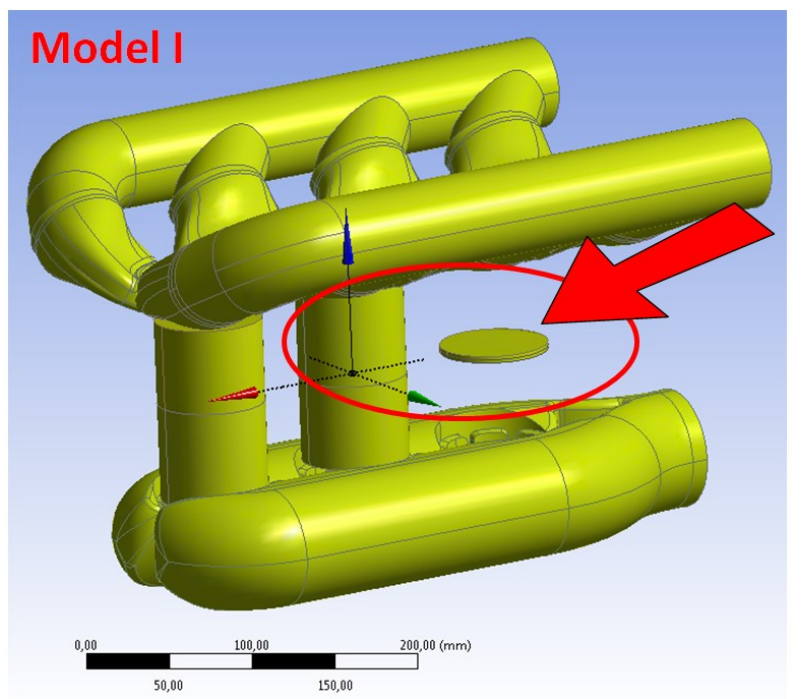

Fig. 3. Geometric model I (flat piston crowns).

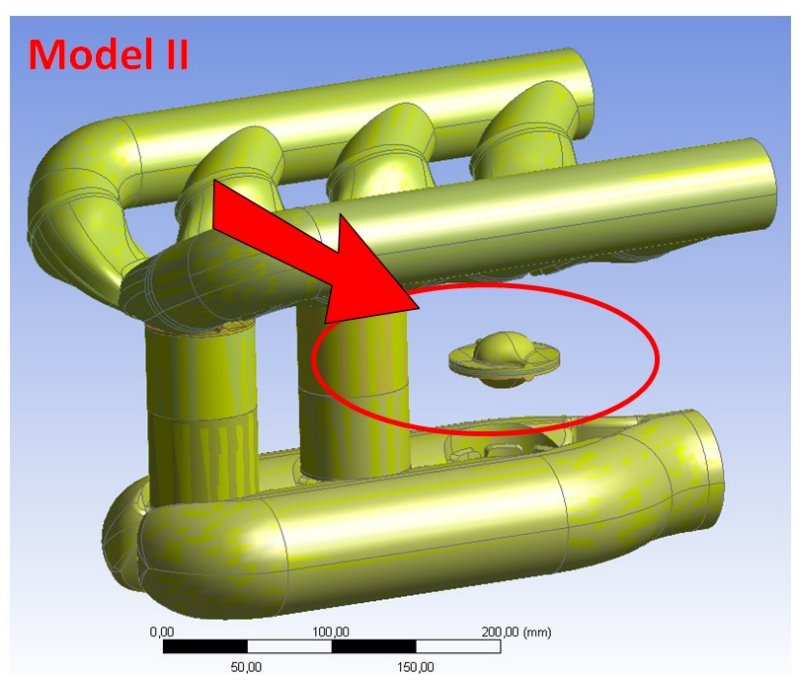

Fig. 4. Geometric model II (specially-shaped piston crowns).

Our aim is to optimise the intake and exhaust manifolds and ports to reduce flow drag, to achieve mass flow growth, uniformity of flow through the intake and outlet ports (uniformity in cylinders) and required strength. 


\section{Methods}

The numerical investigations were carried out using ANSYS FLUENT solver. The geometrical model includes an intake manifold, a cylinder and an outlet manifold. The study was conducted for a series of modifications of manifolds and intake and exhaust ports to optimise the charge exchange process in the engine. A correctly prepared geometric model has enabled us to generate a mesh. In the central part of the cylinder, the mesh consists of hexa-cells, which enables us to simulate motion of pistons by growth of layers using the function of layering. Figures 5 and 6 show the mesh of cylinder 1 (for model I and II, respectively) at the initial position of the pistons. Due to differences in geometric models and initial and boundary conditions, the number of cells in a mesh is minimised but a high quality mesh is maintained. Such an approach has eliminated the impact of mesh on results. The chamber covering the volume between the pistons is divided into two parts so a cut plane was created which was used to generate new layers or delete existing ones when the pistons move.

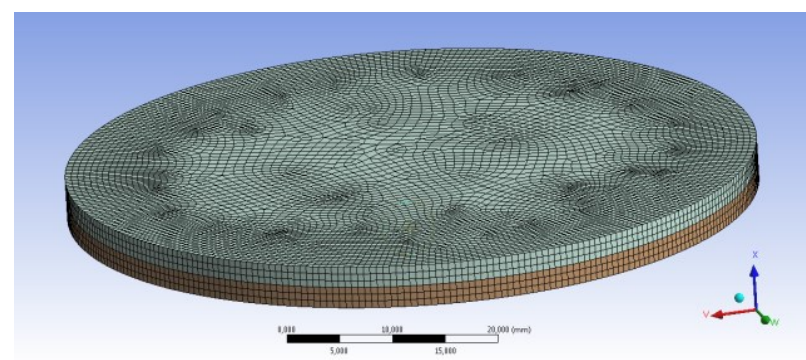

Fig. 5. Mesh of cylinder 1 at the initial position of pistons model I (with flat piston crowns).

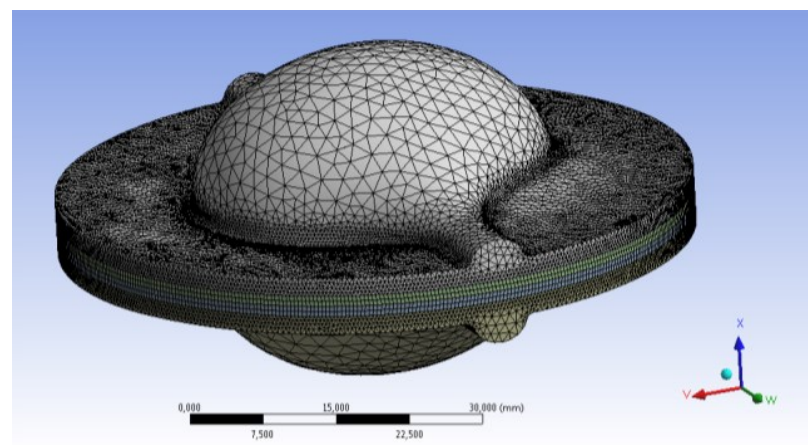

Fig. 6. Mesh of cylinder 1 at the initial position of pistons model II (with specially-shaped piston crowns).

The mesh is created with a wall layer in the ducts. Figures 7 and 8 present the mesh with a visible inflation in the outlet duct and the outlet ports, respectively. The mesh generated for the version with flat piston crowns contains $1,254,985$ nodes and 2,745,017 cells. Correctly shaped piston crowns had an impact on the mesh size. The version with specially-shaped piston crowns contains 1,773,917 nodes and 4,336,244 cells, which is an increase of almost $60 \%$. This is related to the need for separating parallel layers between the pistons and maintaining the smallest possible distance between them. Our calculation assumes the ambient pressure as $101,321 \mathrm{~Pa}$. Relative to the ambient pressure, the outlet pressure of the exhaust manifold was set to $0 \mathrm{~Pa}$ and the temperature to $600 \mathrm{~K}$. The adopted turbulence model is based on the turbulent intensity reduced to $5 \%$ and the turbulent viscosity ratio equal to 10 . Intake duct overpressure was set to $75,000 \mathrm{~Pa}$ and temperature to $325 \mathrm{~K}$.

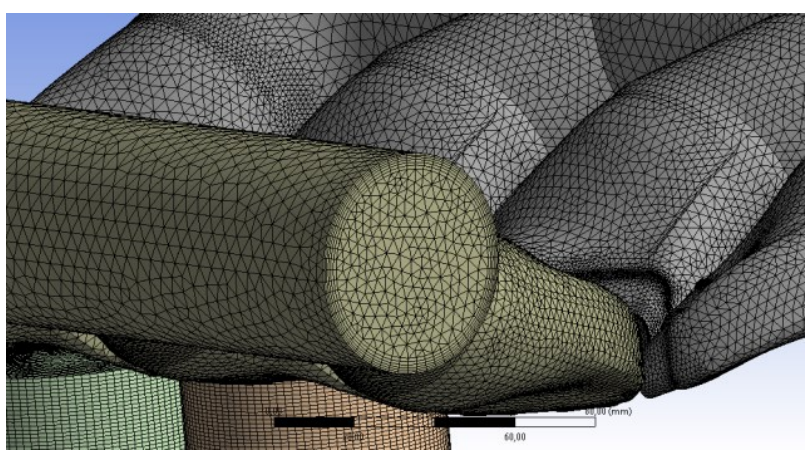

Fig. 7. Mesh with a visible inflation near the exhaust manifold.

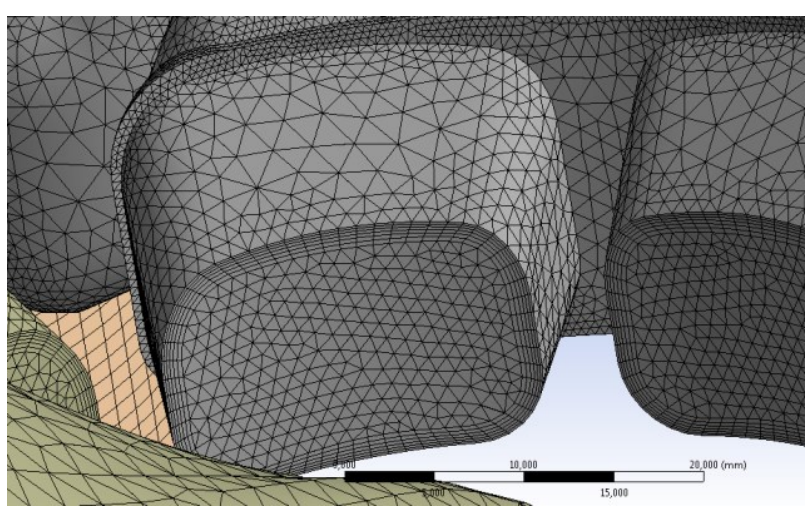

Fig. 8. Mesh with a visible inflation near the outlet ports.

An identical method of describing turbulence for the intake and outlet was defined. For initial volume $\mathrm{Vp}$ (with open intake ports) pressure is $75,000 \mathrm{~Pa}$, which results from the value of boost pressure. The Clausius-Clapeyron Equation was applied to calculate the pressure in each of the cylinders in the output geometry at different levels of compression. Such an approach enabled us to achieve repeatable results at the beginning of the calculation. While initiating the calculations, an additional patch option was applied to enter homogeneous conditions in the selected parts of the computational domain. In the entire domain of the fluid inlet section, pressure was set to $75,000 \mathrm{~Pa}$ and in the fluid outlet section to $0 \mathrm{~Pa}$. In order to verify our calculation, results were monitored by means of speed and pressure contours on the selected planes. The intake and outlet ports are marked according to the pattern given below (Fig. 9).

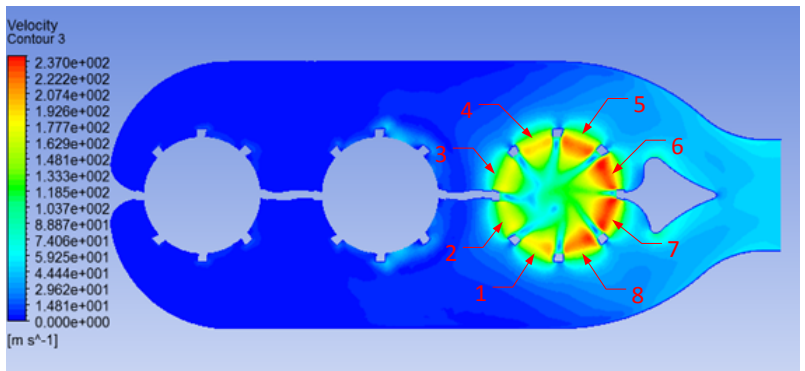

Fig. 9. Marking the intake and outlet ports in the calculation domain. 


\section{Results}

The calculations were carried out for three cycles of cylinder filling. Such a number of cycles enabled us to observe result repeatability. Figures 10-12 show the results as velocity contours under transient conditions in the four control cross-sections for model II. These cross-sections refer respectively to the intake ports (xy), outlet ports (xy), along the cylinders (xz) and simultaneously through ports 4 and 6 . The analogous velocity contours for model II are omitted here due to the very similar nature of flow through the tested ducts. It was decided, however, that the results were to be presented in a quantitative way as charts comparing all of the analysed models.

Figure 13 shows the velocity contours in the plane crossing the intake ports for fully open intake ports in cylinders 1-3.

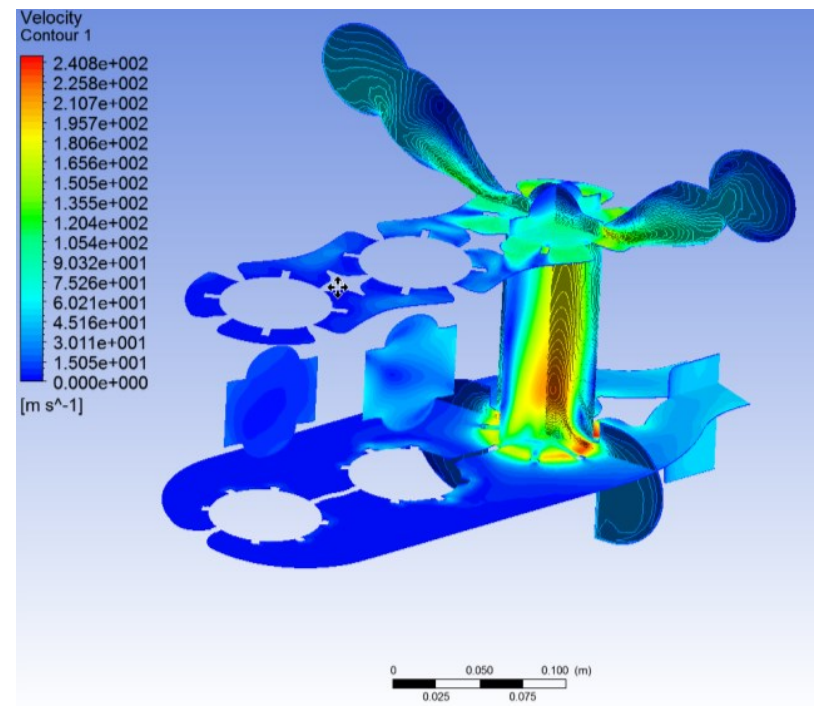

Fig. 10. Speed contours in control planes for fully open intake ports in cylinder 1 - model II.

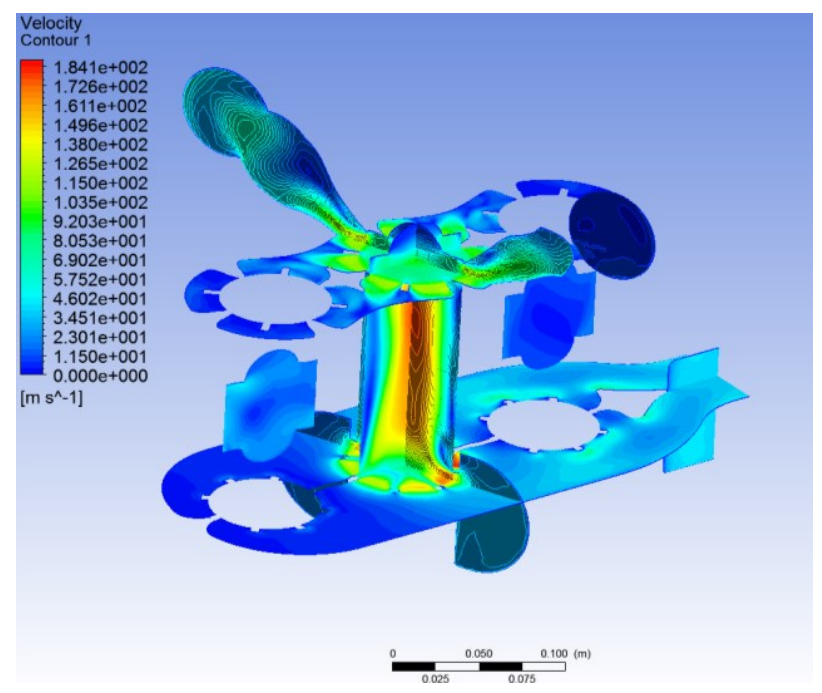

Fig. 11. Velocity contours in control planes for fully open intake ports in cylinder 2 - model II.

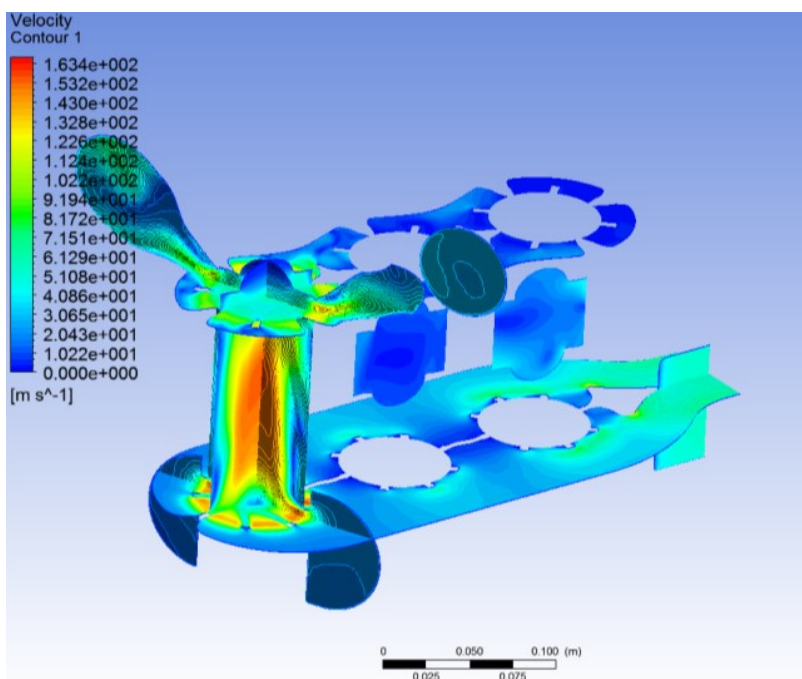

Fig. 12. Speed contours in control planes for fully open intake ports in cylinder 3 - model II.
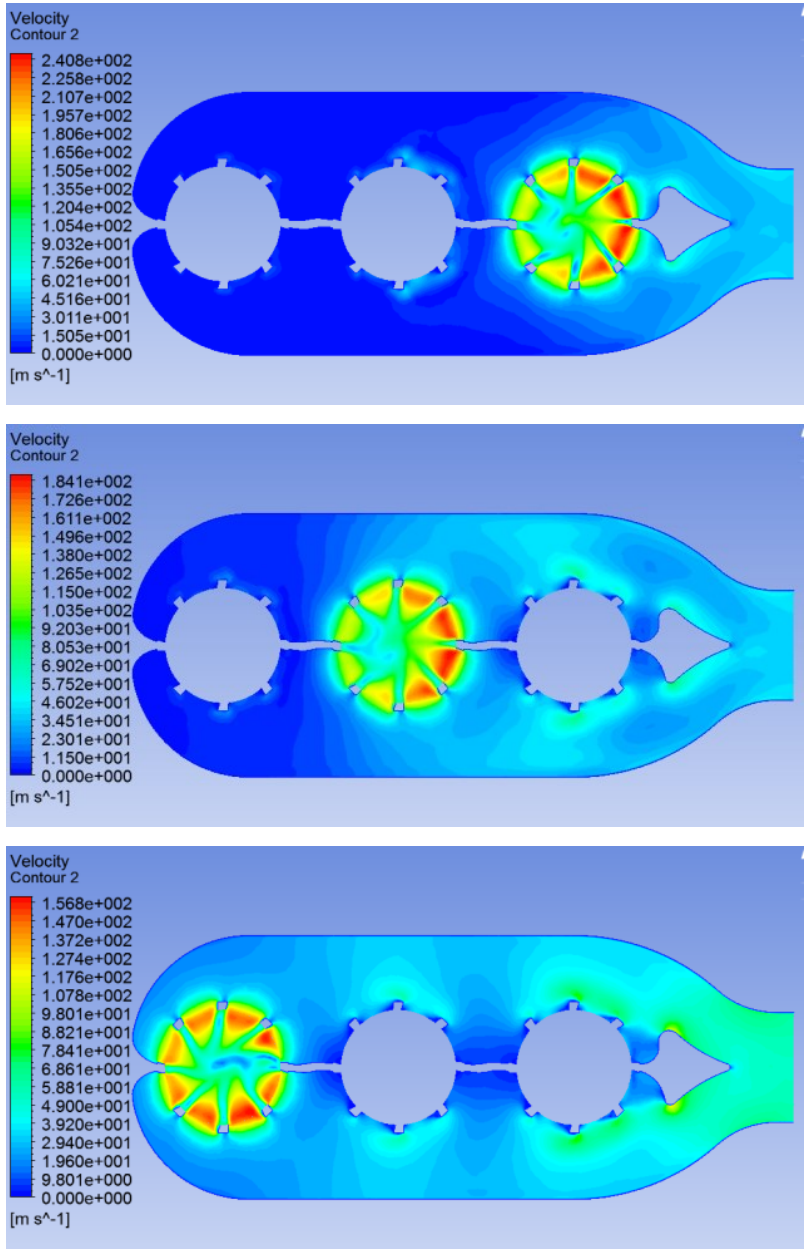

Fig. 13. Velocity contours in the plane crossing the intake ports for fully open intake ports in cylinders 1-3 (down) - model II.

Figure 14 shows the velocity contours in the plane crossing the outlet ports for fully open outlet ports in cylinders 1-3. 

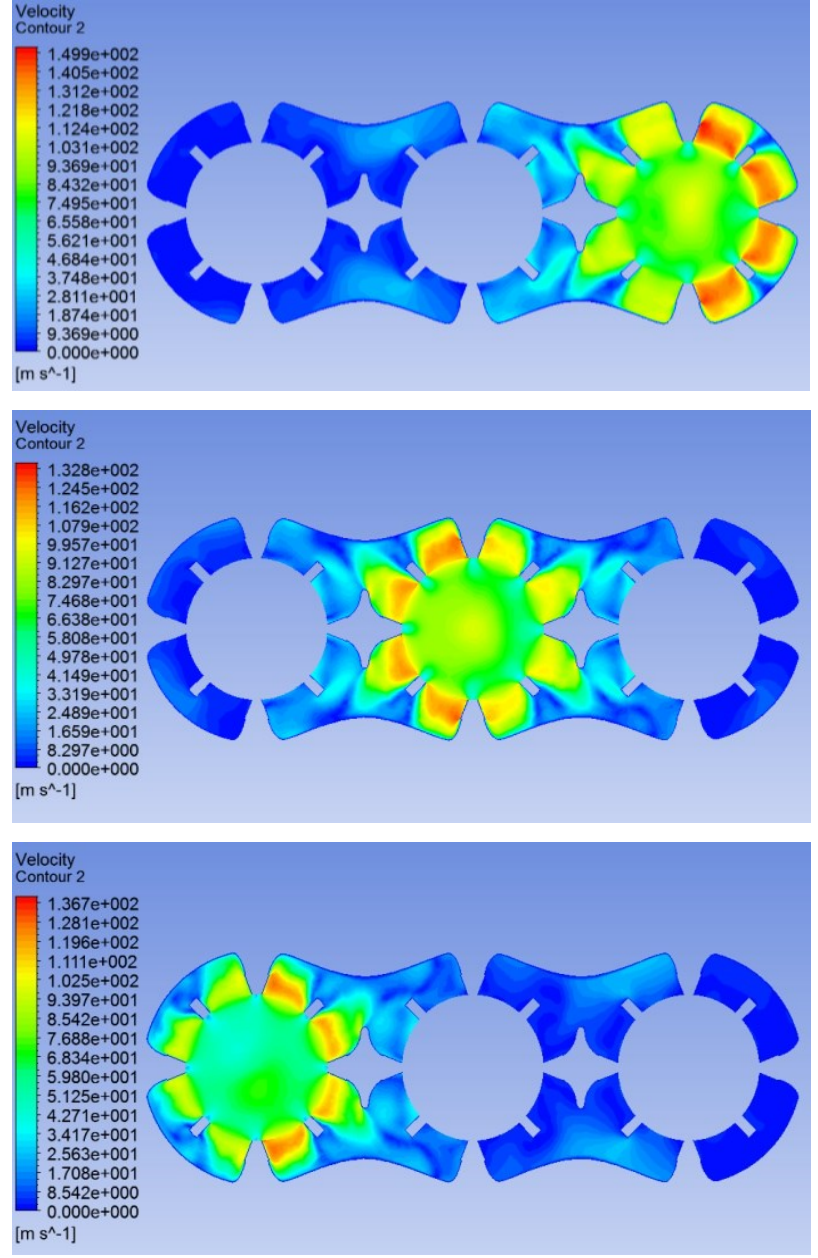

Fig. 14. Velocity contours in the plane crossing the outlet ports for fully open intake ports in cylinders 1-3 (down) model II.

Figure 15 shows the mass flow rate for transient conditions and a reference model calculated for steady conditions.

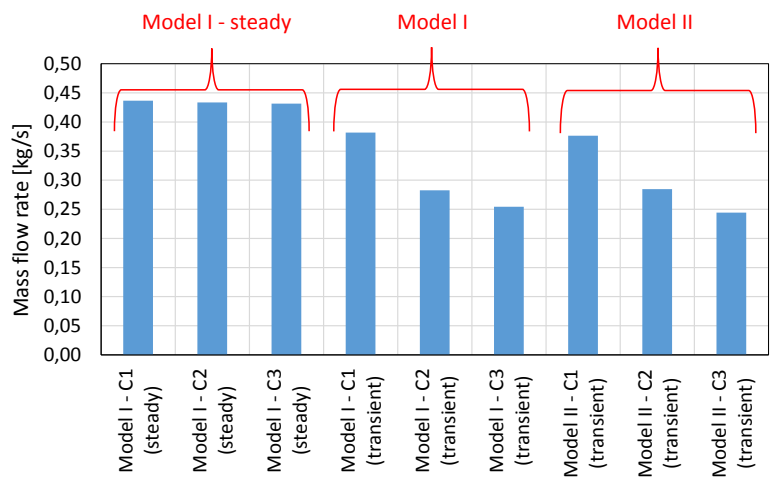

Fig. 15. Mass flow rate for transient conditions and a reference model calculated for steady conditions.

Figure 16 shows mass flow rates in particular intake ports for model I for steady conditions, and Figures 17 and 18 show analogous results for transient conditions.

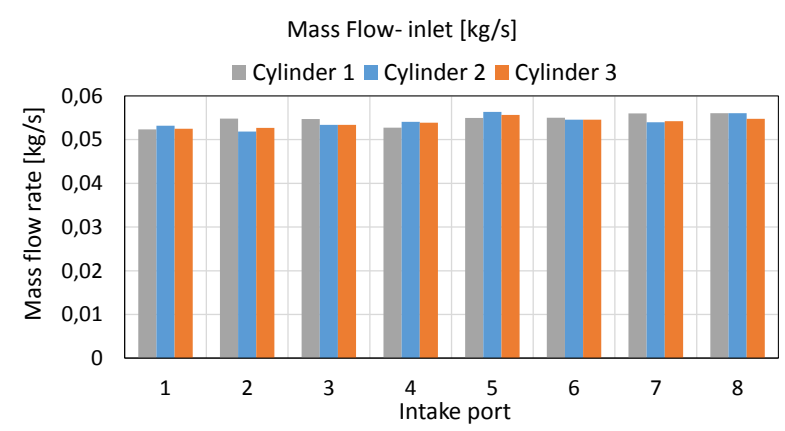

Fig. 16. Mass flow rate under steady conditions in particular intake ports in three cylinders for model I.

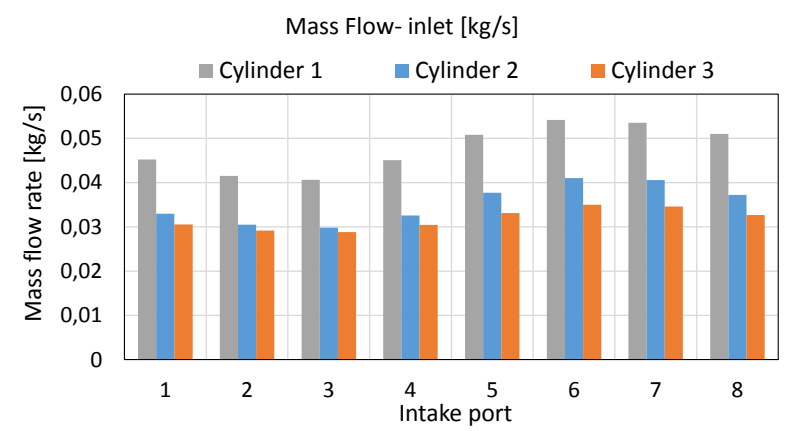

Fig. 17. Mass flow rate under transient conditions in the particular intake ports in three cylinders for model I.

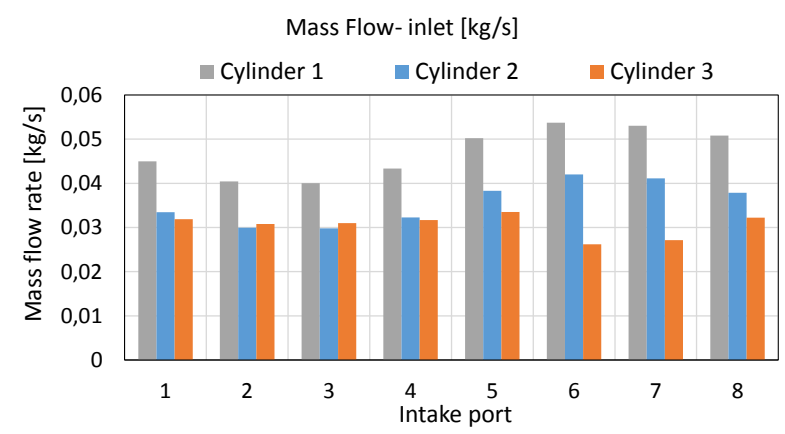

Fig. 18. Mass flow rate under transient conditions in the particular intake ports in three cylinders for model II.

\section{Conclusion}

The results obtained for transient and steady conditions are clearly different. First of all, under steady conditions, the research object had a balanced mass flow rate through the intake and outlet ports in each of the cylinder. The most significant difference in this case was only $1 \%$. However, there is a difference in the mass flow rate under transient conditions for the pistons with flat crowns of $26 \%$ between cylinder 1 and 2 and of $33.4 \%$ between cylinders 1 and 3. Similar correlations can also be noticed in model II. It turns out that under transient conditions for our geometric models the best flow conditions are for cylinder 1 , which is the closest to the intake cross-section. The discrepancy between the cylinders cannot be accepted at this stage and, theoretically, forces us to completely modify the intake system. Unfortunately, the significant difference in the mass flow rate in each port is also accompanied by a significantly decreased value of total charge in relation to that of under steady conditions. Our investigation on the intake system has shown, however, that a short 
intake duct has such an adverse impact (Fig. 3). The intake is too close to the first cylinder. A longer intake duct by $700 \mathrm{~mm}$ positively influenced the mass flow rate and uniformity of flow through the intake port. This proves that our simplified steady state calculation is correct and the uniformity achieved there is valid. Our calculations emphasise that a correctly prepared geometric model - in terms of length of intake ducts - is fundamental in this type of calculation. Too short ducts (applied to reduce the computational domain and shorten the calculation time) constitute a colossal difference in the mass flow rate of particular cylinders.

Acknowledgement: This work has been realised in the cooperation with the Construction Office of WSK "PZL-KALISZ" S.A." and is part of Grant Agreement No. POIR.01.02.00-00-0002/15 financed by the Polish National Centre for Research and Development.

\section{References}

1. W. Balicki, S. Szczeciński, R. Chachurski, A. Kozakiewicz, Problematyka wymiany tadunku $w$ cylindrach lotniczego silnika tłokowego, (Prace Instytutu Lotnictwa, 2009)

2. Z. Czyż, Ł. Grabowski, K. Pietrykowski, J. Czarnigowski, M. Porzak, Measurement, 113 (2018)

3. M. Wendeker, Z. Czyż, Maintenance and Reliability, 18 (2016)

4. Z. Czyż, P. Magryta, Maintenance and Reliability, 18 (2016)

5. K. Siadkowska, A. Majczak, G. Barański, Combust. Engines, 168 (2017)
6. Ł. Grabowski, K. Pietrykowski, P. Karpiński, ITM Web Conf., 15 (2017)

7. M. Szczeciński, P. Mazuro, W. Skrobek, Combust. Engines, 162 (2015)

8. R. Sochaczewski, Z. Czyż, K. Siadkowska, Combust. Engines, 170 (2017)

9. M. Wahl, http://achatespower.com/opposed-pistonengine-history/ (2018)

10. L. Grabowski, Z. Czyż, K. Kruszczynski, SAE Technical Paper 2014-01-2883 (2014)

11. M. Bialy, M. Wendeker, P. Magryta, Z. Czyż, R. Sochaczewski, SAE Technical Paper 2014-01-2575 (2014)

12. C. Abagnale, M. C. Cameretti, L. De Simio, M. Gambino, S. Iannaccone, R. Tuccillo, Appl. Therm. Eng., 65 (2014)

13. H. Karabulut, H. Solmaz, D. Ipci, Appl. Therm. Eng., 121 (2017)

14. R. Sochaczewski, Z. Czyż, K. Siadkowska, Combustion Engines, 170 (2017)

15. M. Costa, G. M. Bianchi, C. Forte, G. Cazzoli, Energy Procedia, 45 (2014)

16. N. B. Hung, S. Jaewon, O. Lim, Energy Procedia, 142 (2017)

17. N. B. Hung O. Lim, Appl. Energy, 178 (2016)

18. J. Czarnigowski, M. Wendeker, P. Jakliński, K. Pietrykowski, A. Nazarewicz, M. Gęca, T. Zyska, SAE Technical Paper 2007-01-2074 (2007) .

19. M. Gęca, M. Wendeker, G. Litak, JVE, 14 (2012) 